\title{
The Delay in Diagnosis of Tuberculosis in the Monteregie region of Quebec, Canada
}

\author{
Caroline Lacroix*†, Philippe Martin $\dagger$, Sebastien Turcotte $\uparrow$, Steven \\ DeRoche $\uparrow$, Vanessa Magluilo $\dagger$ and Christine Lacroix
}

\begin{abstract}
Introduction - Despite being more prevalent in developing countries, tuberculosis (TB) remains an important health problem in Canada. Long diagnosis delays of respiratory tuberculosis are associated with adverse consequences for the patient but also for the community. From a public health perspective, identification of factors associated with long delays of diagnosis could help reduce these delays. Objectives - 1)To describe diagnosis delays of respiratory tuberculosis in Monteregie 2)To identify the characteristics of patients and factors associated with longer diagnosis delays 3)To identify consequences of these delays Methods - The study is descriptive and transversal. Data were obtained from notifiable diseases files of the Public Health Department of the Health and Social Services Agency of Monteregie. The diagnosis delay was calculated using the first symptomatic date and the date of diagnosis. For continued variable analyses, Student t tests and an ANOVA test were done. For categorical variables, Pearson's chi squared test and a Mann-Whitney test were done. Results - The average delay of diagnosis for the 115 cases studied was 92.2 days (CI 80.6-103.8). Weight loss and/or non specific general malaise were associated with a longer diagnosis delay. No association was found between the diagnosis delay and possible consequences of longer delays. Discussion and conclusion: Most patients had a diagnosis delay longer than two months. A larger study that would divide the total diagnosis delay into a patient delay and a suspicion delay (health care system delay) could permit a better identification of factors that favour long delays.

KEYWORDS : Tuberculosis; delay of diagnosis; treatment delay; immigration; consequences of delay
\end{abstract}

\section{INTRODUCTION}

Tuberculosis epidemiology

The World Health Organisation (WHO) estimated that almost one third of the global population was infected by the tuberculosis bacillus in 2006.[1] Presently, approximately 2 million people die each year of the disease. The majority of cases occur in developing countries, but the problem is still important in Canada, despite a constant reduction of the disease incidence in the past 20 years. The increase of immigrants born in countries endemic for tuberculosis (TB) during the past

*To whom correspondence should be addressed:

431 Bolduc

Sherbrooke, Quebec, Canada

J1L $1 \mathrm{H} 8$

Telephone: (819) 791-2806

Fax: (819) 566-4907

Email:Caroline.Lacroix@usherbrooke.ca

†Université de Sherbrooke

†Direction de la santé publique de la Montérégie decades and the more prevalent resistance to treatment in immigrants bring a new challenge to the antituberculosis plan. [1]

In Canada, the majority of new tuberculosis cases occur in the first nation population and immigrants. [1] In Monteregie, approximately 20 cases are declared each year to the Public Health.[2] In 2006, 227 cases were reported in Quebec, from which 19 cases occurred in Monteregie. In Quebec, the incidence was of 3 cases per 100 000; in Monteregie, it was of 1.4 case per 100 000. [3]

\section{Diagnosis}

There are 4 principal methods to establish diagnosis:

1. Pulmonary x-rays: sensitivity of 70 to $80 \%$. [1]

2. Zhiel-Neelsen smear: fast (less than 2 days), sensitivity with and without PCR of $95 \%$ and $60 \%$, respectively. Allows the evaluation of contagiousness of the infected individual; the greater the number of bacillus in each microscopic field, the more contagious 
the individual is. $[1,4]$

3. PCR: in clinical use since approximately 15 years, completed in 3 to 24 hours. Its sensitivity, around $80 \%$, is higher than that of the smear but lower than that for the culture. [1]

4. Culture: The gold standard to establish the diagnosis. Sensitivity around $90 \%$ for 3 sputum cultures. However, it can take up to 6 weeks to obtain results. $[1,4]$

Patients with a positive smear result and those with a pulmonary cavities on $\mathrm{x}$-ray are more contagious than other patients. [4]

\section{Screening for contacts - Public health intervention}

In Quebec, active tuberculosis is a disease that must be mandatorily declared and treated. Because of the potential severity of the disease and the consequences, screening of close contacts of each respiratory tuberculosis case is performed, to detect the presence of disease or latent infection. This process requires human and material resources and generates anxiety in contacts being screened.

\section{Delays of diagnosis}

An important factor in the control of the disease is a rapid diagnosis and instauration of an appropriate treatment. A long delay is associated with a greater risk for the patient to develop a more advanced disease, to have more complications and a higher mortality. $[5,6]$ Also, an increase in the delay causes a higher risk for the community because of the increased contagiousness of the case: the longest delays are associated with larger numbers of bacilli on the smears. [7,8] A systematic review by Storla and al. [9] on delays of diagnosis of tuberculosis described an average total delay of diagnosis of $72 \pm 28$ days.

These findings show that delays of diagnosis represent a major concern for public health and that a decrease in delays could reduce the consequences of tuberculosis. For this reason, it is important to identify factors associated with delays in diagnosis and treatment of TB to make recommendations and develop new methods or protocols to reduce these delays.

The total delay of diagnosis may be divided into different delays. First, there is a delay between the first symptom and the moment when the patient first makes contact with the health care system (patient delay). Next, a delay occurs between the first consultation with a doctor and the beginning of laboratory investigations for tuberculosis (suspicion delay). These two delays combined together represent the pre-test delay. Finally, a delay exists between the first sputum sampling and the confirmation of the diagnosis, either by PCR or by culture (test delay).
The principal factors associated with delays of diagnosis include seropositivity to HIV, chronic cough and/or chronic pulmonary disease, a negative smear result, advanced age, female sex, a low socio-economic status, substance abuse and an immigrant status. [9]

Considering this information, the goal of this study is to describe the delays in diagnosis and treatment of respiratory tuberculosis in Monteregie from 1998 to 2007 , to identify factors associated to these delays and to document some of the possible consequences associated with a prolonged delay.

\section{METHODS}

\section{Population studied}

This cross sectional study includes contagious active tuberculosis cases declared to the Public Health Department (PHD) in Monteregie between January 1st 1998 and June 30th 2007. Because this study concerns contagious tuberculosis, only the pulmonary, laryngeal and miliary forms of the disease were included. The extra-pulmonary cases of tuberculosis that had no respiratory tract involvement were excluded. In order to avoid duplicating data related to a single patient, only the first episode of respiratory tuberculosis identified for each patient in Monteregie during the period studied was considered. The non-confirmed cases (clinical cases, not confirmed by a positive culture or PCR test for a tuberculosis agent) were also excluded to reduce the information bias associated with a wrong diagnosis.

Because the primary objective of the study is to describe the factors associated with delays of diagnosis and treatment of tuberculosis in Monteregie, incidentally found cases were excluded. These cases have a delay of diagnosis of 0 days (the disease start date being the same as the date of diagnosis) and could lead to an underestimation of the delay of diagnosis in symptomatic patients.

\section{Variables studied}

With the information available in the Tuberculosis Epidemiologic Questionnaire of the Public Health Department of the Health and Social Services Agency of Monteregie, three important dates in the diagnostic process of active tuberculosis have been identified: the start date of the disease (which corresponds to the first symptomatic day as recalled by the patient), the first sampling date and the date of diagnosis. The date of diagnosis is defined as the date that tuberculosis was diagnosed for the first time by the treating physician; if this date is unknown, the date of diagnosis was then determined by the date that treatment began or the date of the first positive test result (smear, culture). With these dates, three delays can be evaluated: the pre-test delay, the test delay, and the delay of diagnosis (Table 
1). The data sources available do not identify the date of the first consultation, making it impossible to determine the patient delay and the delay of suspicion. The delay of diagnosis was mostly chosen because it includes the other two that are strongly correlated with it (mostly the pre-test delay) and because the test delay only represents a small fraction of the delay of diagnosis.

With the available information in the diseases files, the presence of an association between the following factors and the duration of the delay of diagnosis was studied (Table 2): year of diagnosis, the exposition of the Health and Social Services Center (HSSC) consulted by the patient to tuberculosis, sex, age, native country (endemic or not) and the number of years since the arrival in Canada in the cases of immigrants, the presenting symptoms, the medical history and the results of diagnostic tests (pulmonary $\mathrm{x}$-rays, smears and PCR).

A second objective of the study is to evaluate the possible consequences of diagnosis and treatment delays of tuberculosis. The four factors analysed to evaluate consequences of the delay are : presence or not

Table 1: Variable Definitions

\begin{tabular}{|c|c|}
\hline Delay of diagnosis & $\begin{array}{l}\text { Number of days between the beginning of the } \\
\text { disease date and the diagnostic date, inclusively }\end{array}$ \\
\hline Pre-test delay & $\begin{array}{l}\text { Number of days between the beginning of the } \\
\text { disease date and the first sputum sampling date, } \\
\text { inclusively }\end{array}$ \\
\hline Test delay & $\begin{array}{l}\text { Number of days between the first sputum } \\
\text { sampling date and the diagnostic date, } \\
\text { inclusively }\end{array}$ \\
\hline Patient delay & $\begin{array}{l}\text { Number of days between the beginning of the } \\
\text { disease date and the first consultation date }\end{array}$ \\
\hline Suspicion delay & $\begin{array}{l}\text { Number of days between the first contact with } \\
\text { the health care system date and the first sputum } \\
\text { sampling date }\end{array}$ \\
\hline $\begin{array}{l}\text { HSSC with a high } \\
\text { exposition to } \\
\text { tuberculosis }\end{array}$ & $\begin{array}{l}\text { A HSSC in Monteregie with an average of at } \\
\text { least } 3 \text { cases of tuberculosis each year between } \\
2004 \text { and } 2006 \text {, according to the statistics from } \\
\text { the Public Health Department of Monteregie } \\
{[10,11,12] \text {. }}\end{array}$ \\
\hline $\begin{array}{l}\text { Endemic native } \\
\text { country }\end{array}$ & $\begin{array}{l}\text { A country with an estimated incidence of } \\
\text { positive smear tuberculosis of at least } 30 \text { cases / } \\
100000 \text { between } 2003 \text { and } 2005 \text {, according to } \\
\text { the Global Health Atlas of the WHO [13] }\end{array}$ \\
\hline $\begin{array}{l}\text { Number of years } \\
\text { since arrival in } \\
\text { Canada }\end{array}$ & $\begin{array}{l}\text { Number of years between the diagnosis and the } \\
\text { arrival in Canada (for immigrants) }\end{array}$ \\
\hline $\begin{array}{l}\text { Presenting } \\
\text { symptoms }\end{array}$ & $\begin{array}{l}\text { Symptoms included in the questionnaire : fever, } \\
\text { nocturnal sweats, weigh loss and/or non specific } \\
\text { general malaise, cough, expectorations, } \\
\text { haemoptysis, thoracic or pleuritic pain }\end{array}$ \\
\hline $\begin{array}{l}\text { Duration of } \\
\text { hospitalisation }\end{array}$ & $\begin{array}{l}\text { Number of days between the admission date and } \\
\text { the end of hospitalisation, inclusively }\end{array}$ \\
\hline Number of contacts & $\begin{array}{l}\text { Number of persons identified as being close } \\
\text { contacts of the index case of tuberculosis during } \\
\text { the standardized inquiry by the PHD }\end{array}$ \\
\hline $\begin{array}{l}\text { Proportion of } \\
\text { contacts with } \\
\text { positive TST }\end{array}$ & $\begin{array}{l}\text { Proportion of index case close contacts that had } \\
\text { a TST result of } 5 \mathrm{~mm} \text { or more in one of the two } \\
\text { tests }\end{array}$ \\
\hline Attribuable deaths & $\begin{array}{l}\text { Death directly caused by or favoured by } \\
\text { tuberculosis }\end{array}$ \\
\hline
\end{tabular}

Table 2: Delays of diagnosis in relation to the different variables studied.

\begin{tabular}{|c|c|c|c|c|}
\hline $\begin{array}{c}\text { Socio-demographic } \\
\text { variables }\end{array}$ & $\begin{array}{l}\text { Number } \\
(\%)^{\mathrm{a}}\end{array}$ & $\begin{array}{l}\text { Aver. delay } \\
\text { of diagnosis } \\
\text { (in days) }\end{array}$ & CI 95\% & $\mathrm{p}$ value \\
\hline $\begin{array}{r}\text { Men } \\
\text { Women }\end{array}$ & $\begin{array}{c}115 \\
72(62.6) \\
43(37.4)\end{array}$ & $\begin{array}{l}90.8 \\
94.4\end{array}$ & $74.5-107.1$ & $0.774^{\mathrm{c}}$ \\
\hline $\begin{array}{r}0-19 \text { years } \\
20-39 \text { years } \\
40-64 \text { years } \\
>64 \text { years }\end{array}$ & $\begin{array}{c}115 \\
8(7.0) \\
25(21.7) \\
35(30.4) \\
47(40.9)\end{array}$ & $\begin{array}{l}71.6 \\
87.8 \\
93.9 \\
96.7\end{array}$ & $\begin{array}{l}24.1-119.2 \\
68.9-106.6 \\
72.0-115.7 \\
77.0-116.4\end{array}$ & $0.752^{d}$ \\
\hline $\begin{array}{r}\text { HSSC } \\
\text { Low exposition } \\
\text { High exposition }\end{array}$ & $\begin{array}{c}115 \\
52(45.2) \\
63(54.8)\end{array}$ & $\begin{array}{l}94.5 \\
90.2\end{array}$ & $\begin{array}{l}74.9-114.1 \\
76.4-104.0\end{array}$ & $0.719^{\mathrm{c}}$ \\
\hline $\begin{array}{r}\text { Native Country } \\
\text { Canada } \\
\text { Endemic country } \\
\text { Other }\end{array}$ & $\begin{array}{c}114 \\
62(54.4) \\
36(31.6) \\
16(14.0)\end{array}$ & $\begin{array}{l}105.1 \\
80.4 \\
73.9\end{array}$ & $\begin{array}{c}87.7-122.5 \\
64.2-96.6 \\
46.1-101.1\end{array}$ & $\begin{array}{l}0.066^{\mathrm{c}, \mathrm{e}} \\
0.102^{\mathrm{c}, \mathrm{f}}\end{array}$ \\
\hline $\begin{array}{r}\text { \# of years since } \\
\text { arrival in Canada } \mathrm{b} \\
0-5 \text { years } \\
>5 \text { years }\end{array}$ & $\begin{array}{c}51 \\
27(52.9) \\
24(47.1)\end{array}$ & $\begin{array}{l}81.7 \\
74.0\end{array}$ & $\begin{array}{l}62.9-100.5 \\
52.3-95.7\end{array}$ & $0.599^{c}$ \\
\hline $\begin{array}{l}\text { Presenting } \\
\text { Symptoms }\end{array}$ & & & & \\
\hline $\begin{array}{|ll|}\text { Fever \& or } & \\
\text { nocturnal sweat } & \\
& \text { Yes } \\
& \mathrm{No}\end{array}$ & $\begin{array}{c}115 \\
66(57.4) \\
49(42.6)\end{array}$ & $\begin{array}{l}99.1 \\
82.8\end{array}$ & $\begin{array}{c}82.9-115.3 \\
66.6-99.0\end{array}$ & $0.175^{\mathrm{c}}$ \\
\hline 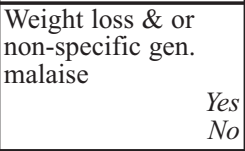 & $\begin{array}{c}115 \\
76(66.1) \\
39(33.9)\end{array}$ & $\begin{array}{c}102.4 \\
72.3\end{array}$ & $\begin{array}{c}88.2-116.6 \\
53.4-91.2\end{array}$ & $0.016^{\mathrm{c}}$ \\
\hline \begin{tabular}{|ll} 
Cough \&/or & \\
expectoration & \\
& Yes \\
& $\mathrm{No}$
\end{tabular} & $\begin{array}{c}115 \\
91(79.1) \\
24(20.9)\end{array}$ & $\begin{array}{l}95.1 \\
81.0\end{array}$ & $\begin{array}{l}82.0-108.2 \\
56.3-105.7\end{array}$ & $0.335^{\mathrm{c}}$ \\
\hline Haemoptysis & $\begin{array}{c}97 \\
20(20.6) \\
77(79.4)\end{array}$ & $\begin{array}{c}109.0 \\
85.1\end{array}$ & $\begin{array}{l}78.0-140.0 \\
72.1-98.1\end{array}$ & $0.122^{b}$ \\
\hline \multicolumn{5}{|l|}{ Antecedents } \\
\hline Smoking & $\begin{array}{c}61 \\
19(31.1) \\
42(68.9)\end{array}$ & $\begin{array}{l}88.7 \\
98.9\end{array}$ & $\begin{array}{l}64.0-113.4 \\
75.9-121.9\end{array}$ & $0.599^{\mathrm{c}}$ \\
\hline $\begin{array}{|ll|}\text { Known contact } \mathrm{w} & \\
\text { TB pxt } & \mathrm{Yes} \\
& \mathrm{No}\end{array}$ & $\begin{array}{c}94 \\
40(42.6) \\
54(57.4)\end{array}$ & $\begin{array}{l}88.8 \\
91.1\end{array}$ & $\begin{array}{l}68.4-109.2 \\
75.0-107.2\end{array}$ & $0.865^{\mathrm{c}}$ \\
\hline $\begin{array}{l}\text { HIV sero(+)ve \& or } \\
\text { immunosupp. } \\
\qquad \begin{array}{l}\text { Yes } \\
\text { No }\end{array}\end{array}$ & $\begin{array}{c}71 \\
7(9.9) \\
64(90.1)\end{array}$ & $\begin{array}{l}112.3 \\
85.5\end{array}$ & $\begin{array}{l}51.4-173.2 \\
70.4-100.6\end{array}$ & $0.295^{\mathrm{c}}$ \\
\hline 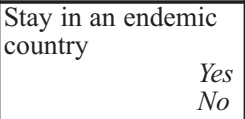 & $\begin{array}{c}105 \\
40(38.1) \\
65(61.9)\end{array}$ & $\begin{array}{l}82.9 \\
94.1\end{array}$ & $\begin{array}{l}64.9-100.9 \\
79.2-109.0\end{array}$ & $0.356^{\mathrm{c}}$ \\
\hline \multicolumn{5}{|l|}{ Paraclinic Tests } \\
\hline $\begin{array}{l}\text { Chest Xray result } \\
\text { Norm or Abnorm } \\
\text { Abnorm Cavitary }\end{array}$ & $\begin{array}{c}115 \\
88(76.5) \\
27(23.5)\end{array}$ & $\begin{array}{l}91.0 \\
95.9\end{array}$ & $\begin{array}{l}77.9-104.1 \\
70.8-121.0\end{array}$ & $0.729^{c}$ \\
\hline $\begin{array}{r}\text { Positive } \\
\text { Negative }\end{array}$ & $\begin{array}{c}111 \\
67(60.4) \\
44(39.6)\end{array}$ & $\begin{array}{l}93.7 \\
89.3\end{array}$ & $\begin{array}{l}79.7-107.7 \\
69.7-108.9\end{array}$ & $0.711^{\mathrm{c}}$ \\
\hline $\begin{array}{r}+ \text { or }- \\
\text { No PCR done }\end{array}$ & $\begin{array}{c}115 \\
77(67.0) \\
38(33.0)\end{array}$ & $\begin{array}{l}89.3 \\
97.9\end{array}$ & $\begin{array}{l}76.4-102.2 \\
74.2-121.6\end{array}$ & $0.498 \mathrm{c}$ \\
\hline
\end{tabular}

a Proportion expressed in percentage of the total of valid cases for each variable; ${ }^{b}$ For immigrants only; ${ }^{c}$ Student $t$ test; ${ }^{d}$ ANOVA test; e Comparison of the average delays of diagnosis between Canadian born patients and foreign-born patients of endemic countries; $f$ Comparison of the average delays of diagnosis between Canadian born patients and foreign-born patients of non-endemic countries (beside Canada) 
of hospitalisation of the patient and its duration if present, total number of contacts, proportion of contacts with a positive TST and the number of deaths attributed to tuberculosis (caused entirely or partially by tuberculosis).

\section{Measurement instrument and data collection}

Data collection was realised with a data gathering tool elaborated from the available information in the notifiable diseases files of the patients (Appendix 4). The information used in this study was obtained from the Tuberculosis Epidemiologic Questionnaire (Appendixes 5,6) which is an integral part of the standardized inquiry of the PHD and is filled out for all cases of tuberculosis reported in Monteregie. This document is kept in the archives of the transmissible diseases program of the PHD of Monteregie.

To confirm the validity of the data gathering tool elaborated and to reduce the inter-observer variability, it was pre-tested on 15 cases chosen randomly, after which minor modifications were done and a consensus on the way to collect data was established. The cases used for the pre-test were not eliminated from the study because the data gathering tool is used to review files, not to survey patients (results are therefore not influenced by question formulation).

When imprecise dates were reported in the patient files, for example "beginning of the month", "middle of month" or "end of month" it was decided to transcribe them as the 1st, the 15 th or the 30th (28th for February) of the month, respectively. Data not found in the questionnaires were transcribed as "unknown".

The information obtained with the data gathering tool was then transferred in a data bank using the program "Statistical Package for Social Sciences (SPSS) version 15.0. (SPSS Inc, Chicago)" A complete verification of the data bank was done to minimise transcription errors.

\section{Analysis}

To establish the statistical signification of the results obtained, a Student $t$ test was done for the analysis of continuous variables, such as factors associated with delays of diagnosis. An ANOVA test was used for the evaluation of the delay in diagnosis as a function of patient age. A Mann-Whitney test was used to analyse the number of close contacts as a function of the delay in diagnosis, because the values taken by the first variable deviated largely from a standard distribution. A Pearson Chi-squared test was used to analyse nominative variables. For each statistical test done, the signification threshold was fixed at 0.05 .

\section{Ethical aspects}

This study was done under the supervision the Public
Health Department of Monteregie and its objective is part of the public health mandate. The confidentiality of the cases studied was preserved with many precautions, including non nominative data collection.

\section{RESULTS}

A total of 206 cases of TB were declared to the PHD of Monteregie between January 1st 1998 and June 30th 2007. From this number, 65 were non-respiratory TB and 7 respiratory cases were clinical ones not confirmed by culture or PCR. There were 134 cases of active tuberculosis validated. From this number, 11 were incidentally found and were excluded for the study. Eight others were excluded during data collection: 4 files were not found at the time of data collection, a fifth case was excluded because the file was incomplete, another was excluded because the delay of diagnosis could not be determined (the first symptomatic date was not identified) and the last two cases were in fact recurrences in patients with a previous episode of TB already declared to the PHD of Monteregie. The population studied represents a total of 115 cases.

\section{Description of the population studied}

All of the cases presented at least one pulmonary TB component. For the immigrants, the median number of years between arrival in Canada and the diagnosis was 5 years. Table 2 presents the principal characteristics of the cases studied. The population is composed of a larger number of men compared to women, of people mostly aged more than 40 years and of people mostly native from Canada.

\section{Delays of diagnosis}

The different delays analysed in this study are presented in table 3 . The average delay of diagnosis is 92.2 days and the median delay is 83.0 days.

\section{Factors associated with the delay of diagnosis}

Many factors were analysed to evaluate the presence of association with the length of the delay of diagnosis. None of the sociodemographic variables studied (sex, age, HSSC and native country) were statistically significantly associated with differences in the delay of diagnosis. Individuals native from endemic countries for tuberculosis seemed to have a shorter delay of diagnosis than those born in Canada; the $p$ value found for this relation is near but not below the 0.05 threshold.

Only one presenting symptom studied was statistically associated with a delay of diagnosis: weight loss and/or non specific general malaise was associated with a longer delay of diagnosis (102.4 days) than if that symptom is absent at presentation (72.3 days). 


\section{Possible consequences of delays of diagnosis}

To evaluate the presence of an association between possible consequences of delays of diagnosis studied and the delay of diagnosis, delays were classified as long or short. The results of the study show that a delay of diagnosis of 100 days coincided with the 64th percentile. It was arbitrarily decided that a delay of 100 days or more was a long delay and that a delay of less than 100 days was a short delay.

None of the possible consequences of delays of diagnosis (number of contacts, presence or absence of hospitalisation and number of days of hospitalisation) were related to the duration of the delays. The overall proportion of positive TCT results for close contacts of the index case was compared to an analysis that included only cases with patients native from an endemic country for TB. There was no significant difference in the results obtained.

\section{DISCUSSION}

This study describes for the first time delays in diagnosis and treatment of tuberculosis in Monteregie. During the period studied, the population of confirmed tuberculosis cases is nearly complete because laboratories declared all cases of the disease, tuberculosis being subject to mandatory declaration.

\section{Discussion of results}

The average delay of diagnosis was 92.2 days and is similar to results obtained in the systematic review by Storla et al. [9] (72 days \pm 28 days).

Table 3: The different delays analysed in this study

\begin{tabular}{|l|c|c|c|c|}
\hline Delays & $\begin{array}{c}\text { Median delay } \\
\text { (days) }\end{array}$ & $\begin{array}{c}\text { Average delay } \\
\text { (days) }\end{array}$ & CI 95\% & $\begin{array}{c}\text { Range } \\
\text { (days) }\end{array}$ \\
\hline $\begin{array}{l}\text { Delay of } \\
\text { diagnosis }\end{array}$ & 83.0 & 92.2 & $80.6-103.8$ & $(3,344)$ \\
\hline $\begin{array}{l}\text { Pre-test } \\
\text { delay }\end{array}$ & 61.0 & 76.1 & $64.9-87.3$ & $(0,335)$ \\
\hline Test delay & 7.0 & 15.0 & $11.6-19.4$ & $(-4,133)$ \\
\hline
\end{tabular}

In the notifiable diseases files of patients, the date of first consultation was not available. It was impossible to divide the total delay of diagnosis into patient and suspicion delay as was often done in other studies. In some studies $[14,15]$, it was found that the two delays were not influenced by the same factors and that a particular factor could influence the two delays in opposite ways. For example, being an immigrant can increase the patient delay but reduces the delay of suspicion; the final effect on delay of diagnosis is therefore difficult to predict.

For the relation between the delay of diagnosis and patient age, a tendency of increased delay was observed with older patients using four age sub-divisions (shown in Table 2). This observation is reported in other studies [9], where an advanced age is a risk factor for a longer delay of diagnosis. This relation was not statistically significant, but motivated a second analysis with only two age divisions: less than 40 years and 40 years or older. This second analysis in turn did not show a statistically significant result.

No significant relation was observed between the exposition of the Health and Social Services Center to tuberculosis and the delay of diagnosis. It was believed that the HSSC with a higher exposition to the disease would have shorter delays of diagnosis. However, an information bias exists since the HSSC identified for each patient is established with the patient address at the time he had the disease and is therefore not necessarily the one where the patient first consulted a doctor. Also, the number of cases of TB in all HSSC is small, the largest number of cases per HSSC being 10 per year. The difference between HSSC is likely minimal.

In this study, a shorter average delay of diagnosis (80.4 days) was observed for immigrants native from an endemic country (a country with an estimated incidence of positive smear tuberculosis of at least 30 cases / 100 000) than for patients born in Canada (105.1 days). The $\mathrm{p}$ value for this relation, at 0.066 , is not below the 0.05

Table 4: The possible consequences studied in relation to delays of diagnosis

a Proportion expressed in percentage of the total of valid cases for each variable

\begin{tabular}{|c|c|c|c|}
\hline & Short Delay & Long Delay & $\mathrm{p}$ value \\
\hline $\begin{array}{r}\text { Number of cases concerned }(\%)^{\mathrm{a}} \\
\text { Average number of contacts (CI } 95 \%) \\
\text { Median number of contacts }\end{array}$ & $\begin{array}{l}64(61.5) \\
15.1(7.1-23.2) \\
7.0\end{array}$ & $\begin{array}{l}40(38.5) \\
13.7(10.5-16.8) \\
13.0\end{array}$ & 0.123 \\
\hline $\begin{array}{r}\text { Positive TST results among close contacts } \\
\text { Number of cases concerned (\%) } \\
\text { Average proportion of +ve results among close contacts (CI 95\%) }\end{array}$ & $\begin{array}{l}60(60.6) \\
0.419(0.329-0.509)\end{array}$ & $\begin{array}{l}39(39.4) \\
0.393(0.303-0.483)\end{array}$ & 0.703 \\
\hline $\begin{array}{r}\text { \# of pxts hospitalised (\%) } \\
\text { \# of pxts non hospitalised (\%) }\end{array}$ & $\begin{array}{l}50(68.5) \\
21(52.5)\end{array}$ & $\begin{array}{ll}23 & (31.5) \\
19 & (47.5)\end{array}$ & 0.107 \\
\hline Average duration of hospitalisation (days) (CI 95\%) & $25.9(18.8-33.0)$ & $26.5(8.9-44.1)$ & 0.951 \\
\hline Outcome of the disease & $\begin{array}{l}56(64.4) \\
9(0.6)\end{array}$ & $\begin{array}{l}31(35.6) \\
6(0.4)\end{array}$ & 0.776 \\
\hline
\end{tabular}


threshold. It is possible that the number of cases studied was not sufficient to establish a statistically significant association. This relation, if found to be true, could be explained by the fact that clinicians will include tuberculosis in their differential diagnosis more readily in an foreign born than in a Canada born patient because the disease is less prevalent in Canada. This hypothesis is supported by other studies $[14,15,16]$ that show the health care system associated delay is shorter for foreign patients. A previous stay in an endemic country, which was also verified in each case, seemed to follow this trend.

A longer delay of diagnosis was observed in the presence of each presenting symptom. These relations were not statistically significant except for the weight loss and/or non specific general malaise ( $p$ value of 0.016.) This is not consistent with the current literature where certain symptoms are associated to longer delays (ex: cough) and other with shorter delays (ex: fever) $[9,17]$. These observations could be explained by the fact that a long delay of diagnosis favours disease progression and therefore symptom appearance. Also, non-specific symptoms could lead to longer suspicion delays by the clinician.

Smoking, a known contact with a tuberculous patient, and a stay in an endemic country are not significantly associated with a shorter delay of diagnosis. It was believed that the presence of certain medical conditions would lead to shorter delays of diagnosis. First, smoking is associated to lung cancer. Tuberculosis and lung cancer share many symptoms: cough, haemoptysis, weight loss, etc. Clinicians who face a patient that smokes and presents some of these symptoms have to rule out lung cancer, requiring a more in-depth investigation. However, an information bias for smoking is probably present, because this information was not systematically indicated in all the questionnaires. The hypothesis of a shorter delay in patients with a known contact with another tuberculosis case or a stay in an endemic country came from the assumption that clinical suspicion would be higher in these patients. However, clinicians might not ask their patients these important questions.

Smear results and pulmonary x-ray results do not significantly influence the delay of diagnosis. A positive smear result or a cavitary pulmonary x-ray is logically associated with a faster diagnosis. However, the absence of such an observation in this study could be due to a long delay before consultation with a doctor or to a longer suspicion delay by the clinician, prolonging the delay of diagnosis. Use of PCR for investigating tuberculosis reduces the average delay of diagnosis in the cases studied, but the relation is not significant.

For the possible consequences of delays of diagnosis, the median number of contacts increases with the duration of the delay but the relation is not statistically significant. The number of contacts retrieved in the patient file depends on the extent of the inquiry made by the PHD and depends on the social environment (work, school, family, etc.) of the index case. The number of investigated contacts is possibly more dependant on social environment than on the duration of the contagious period. This hypothesis cannot be verified with the available data.

The proportion of infected contacts (established by a positive TST result) would logically be higher if the contagious period is prolonged, but the contact lists retrieved in patient files were often incomplete and a recall bias is therefore possible. A more structured contact list separating close contacts from other contacts could offer more interesting research data. Interestingly, division according to native country did not modify the relation observed.

Hospitalized patients often have a shorter delay of diagnosis, but the relation observed is not significant. This could be explained by the fact that hospitalization permits a faster management of the patient and favours a faster diagnosis. A study of a larger population is suggested to obtain a statistically significant relation.

There is no significant difference of treatment outcome (recuperation or death) between the long and short delay groups. Three cases were diagnosed postmortem making the delay of diagnosis difficult to establish because the first symptom date is not known. The number of deaths caused or favoured by TB is limited. A larger study should be done to determine the association between delay of diagnosis and treatment outcome.

\section{Principal limitations of study}

Exclusion of clinical cases (not confirmed by culture or PCR results) reduces the number of cases studied. Also, these cases may have longer delays of diagnosis and the factors associated with them could be different. However, the number of these case is limited (only 7) and is not significant compared to the total number of cases studied (115).

Even if the data bank used included all the respiratory cases of tuberculosis declared in Monteregie between 1998 and June 2007, the statistical power of the study is low; the number of cases may be insufficient to obtain other statistically significant associations.

This study, being descriptive and transversal, cannot establish links of causality between the variables studied. It is only possible to identify the presence of an association between them.

The date when the disease began, needed to establish the delay of diagnosis, is determined by asking the 
patient to identify the moment where he or she first noticed symptoms. This could result in a recall bias because the patient does not necessarily remember the precise date of symptom appearance. Also, it is difficult to determine if that symptom was really caused by TB.

Secondary utilisation of data in this study can result in a recall bias. For most variables, the fact that questions were asked in an inquiry context rather than for research purposes probably did not significantly influence the results. However, for certain questions, the lack of strict term definitions and questions asked with different wording can diminish the value of the information obtained.

\section{External validity}

The external validity of the study is good enough to extend the results obtained to the population of Monteregie for the next years, because all confirmed cases of pulmonary TB during the studied years were included. However, results cannot be extended to other regions, because sociodemographic characteristics of the population and healthcare organization may vary from those found in Monteregie.

\section{CONCLUSION AND RECOMMENDATIONS}

The average delay of diagnosis of TB in Monteregie between January 1st 1998 and June 30th 2007 is similar to delays described in the literature. [9] Weight loss and/or non specific general malaise are associated to a longer delay of diagnosis. No other factors associated to delays were statistically significant. No possible consequence analysed could be attributed to a longer delay. Limits of the study have to be considered; these include a population possibly too small to obtain statistically significant results for the analyses made.

\section{Recommendations}

1. This study, being descriptive and transversal, does not allow the identification of factors of causality between delays in diagnosis and factors associated to these delays or consequences of these delays. In addition, most results were not statistically significant, making it difficult to determine factors that could help in the early diagnosis of TB. However, since the delays in diagnosis of TB remain long, physicians should be informed on the importance of an early diagnosis and thus a high clinical suspicion of TB.

2. A systematic tool to trace contacts and gather follow-up information would be useful for future studies. A summary sheet organising patients according to the relative importance of their contact with the index case would give a better appreciation of the chain of contagiousness and allow more easy access to the relevant information.
3. The first consultation date could be added to public health TB questionnaires in order to differentiate patient delays from health care system delays. This information would allow a better determination of the relative importance of each type of delay, and a better identification of interventions to correct factors causing delays in diagnosis of TB.

\section{ACKNOWLEDGMENTS}

The original study was done by five third grade medical students of the Universite de Sherbrooke, during their public health training of the medical internship in the Public Health Department of the Health and Social Services Agency of Monteregie.

They also thank everyone that contributed in a certain way to the accomplishment of this work: Mrs Caroline Gélinas, technician in psychosocial study; Mrs Ginette Lagarde, public health nurse; Dr Éric Levac, consulting physician of the transmissible diseases sector.

\section{REFERENCES}

1. Agence de la santé publique du Canada. Normes Canadiennes pour la lutte antituberculeuse 6e édition - 2007. http://www.phac-aspc.gc.ca/tbpc-latb/pubs/tbstand07-fra.php

2. Direction de la santé publique de la Monteregie, Bulletin Sentinelle, années $2003 \quad 2006$. http://www.rrsss16.gouv.qc.ca/Menu_Gauche/4-Publications/2Bulletins/Bulletins_de_la_Sante_publique/Sentinelle/sentinelle theme.html

3. Agence de la santé publique du Canada. La tuberculose au Canada - 2006, prédiffusion. http://www.phacaspc.gc.ca/publicat/2007/tbcanpre06/index-fra.html

4. Southwick FS. Pulmonary infections. In: Southwick FS, editor. Infectious Diseases in 30 days. United states of America, McGraw Hill; 2003. P 107-153

5. Zafran N, Heldal E, Pavlovic S, Vuckovic D, Boe J. Why do our patients die of active tuberculosis in the era of effective therapy? Tubercle and Lung Disease. 1994; 75(5): 329-333.

6. Enarson D. Failure of diagnosis as a factor in tuberculosis mortality CMAJ. 1978; 118 : 1520-1522.

7. Madebo T, Lindtjorn B. Delay in treatment of pulmonary Ttuberculosis : An analysis of symptom duration among Ethiopian patients. Medscape General Medicine. 1999: E6.

8. El-Sony A, Enarson D, Khamis A, Baraka O, Bjune G. Relations of grading of sputum smears with clinical features of tuberculosis in patients in routine practice in Sudan. Int $\mathrm{J}$ Tuberc Lung Dis. 2002; 6(2): 91-97.

9. Storla DG. Yimer S. Bjune GA. A systematic review of delay in the diagnosis and treatment of tuberculosis. BMC Public Health. 2008; 8(1) : 15-22.

10. Perron L, Levac E et al. Rapport annuel 2006 - Les maladies infectieuses en Montérégie, incluant les maladies à déclaration obligatoire (MADO). Agence de la santé et des services sociaux de la Montérégie, juin 2007. http://www.rrsss16.gouv.qc.ca/Menu_Gauche/4-Publications/3Monographies_Orientations_Rapports/Maladies_transmissibles /dsp_pub_rap_mado_2006.pdf

11. Lina Perron, Louise de la Boissière et al. Les maladies infectieuses en Montérégie, incluant les maladies à déclaration obligatoire (MADO) - Rapport annuel 2005. Agence de la santé et des services sociaux de la Montérégie, juin 2006. 
http://www.rrsss16.gouv.qc.ca/Menu_Gauche/4-Publications/3Monographies_Orientations_Rapports/Maladies_transmissibles /dsp_pub_rap_mado_2005.pdf

12. Éric Levac, Julie Loslier et al. Maladies à declaration obligatoire d'origine infectieuse - Rapport annuel 2004. Agence de développement de réseaux locaux de services de santé et de services sociaux, avril 2005.

http://www.rrsss16.gouv.qc.ca/Menu_Gauche/4Publications/3Monographies Orientations Rapports/Maladies transmissibles/dsp_pub_rap_mado_2004.pdf

13. World Health Organisation. Communicable diseases, Tuberculosis. http://www.who.int/globalatlas/dataQuery/ default.asp

14. Fara MG, Rygh JH, Steen T.W, Selmer R, Heldal E, Bjune G. Patient and health care system delays in the start of tuberculosis treatment in Norway. BMC Infectious Diseases. 2006; 6(33).

15. Gagliooti C, Resi D, Moro ML. Delay in the treatment of pulmonary $\mathrm{TB}$ in a changing demographic scenario, International Journal of Tuberculosis and Lung Disease. 2006; 10(3): 305-309.

16. Rodger A, Jaffar S, Paynter S, Hayward A, Carless J, Maguire H. Delay in the Diagnosis of Pulmonary Tuberculosis., London, 1998-2000 : Analysis of surveillance data. BMJ. 2003; 326(7395): 909-910.

17. Sanz B, Blasco T. Variables associated with diagnostic delay in immigrant groups with tuberculosis in Madrid. International Journal of Tuberculosis and Lung Disease. 2007; 11(6): 639646.

Caroline Lacroix (M.D. 2009) is currently an M.D. student at the Université de Sherbrooke.

Philippe Martin (M.D. 2009) is currently an M.D. student at the Université de Sherbrooke.

Sebastien Turcotte (M.D. 2009) completed four years of undergraduate studies in the fields of science and engineering at the University of Ottawa. He is currently an M.D. student at the Université de Sherbrooke.

Vanessa Magluilo (M.D. 2009) is currently an M.D. student at the Universite de Sherbrooke.

Steven DeRoche (M.D. 2009) is currently an M.D. student at the Université de Sherbrooke.

Christine Lacroix (M.D., M.Sc.) is a community medicine specialist working in infectious diseases control at the Direction de santé publique de la Montérégie. 